\title{
New Moisture Control System of Coal for Coking*
}

\author{
By Shinjiro WAKURI,** Moriyoshi OHNO, ,* Katsuya HOSOKAWA,** \\ Koichiro NAKAGAWA, ** Yutaka TAKANOHASHI, ** Teruaki OHNISHI,** \\ Kiyoshi KUSHIOKA*** and Yoshimitsu KONNO***
}

\begin{abstract}
Synopsis
Coke oven operations are greatly affected by the properties of charging coal. Especially, fluctuations of moisture content of charging coal have a great adverse effect on the stable operation of coke ovens. We have always aimed at an ideal operational condition that the moisture content of charging coal is reduced and controlled economically to a constant level regardless of weather. For this purpose, the new control technique of coal moisture using waste heat from coke ovens effectively was developed successfully. The first equipment of this process came on stream at Nos. 1 and 2 coke oven batteries of Oita Works in September, 1983. The operation results have been better than expected.

Features of this equipment are as follows:

(1) This equipment is able to apply to coke oven in operation.

(2) The moisture content of charging coal is controlled to $5 \%$.

(3) The whole of charging coal is dried.

(4) In this process, the sensible heat of combustion waste gas from coke oven and of generated gas in coke oven recovered by heat exchangers using a heat carrying medium. This recovered heat is utilized at a dryer and the heat carrier is recirculated.
\end{abstract}

(5) The capacity of dryer is $260 t$-dry coal/h and the moisture content of charging coal can be reduced from 11 to $5 \%$. Moisture content can be reduced from 9 to $5 \%$ using only the recovered heat. For reducing from 11 to $9 \%$, a heating furnace is installed to heat circulating medium up.

The effects of this process are a decrease in heat consumption (actual: 90 93 Mcal/t-dry coal, expected: $78 \mathrm{Mcal} / \mathrm{t}-\mathrm{dry}$ coal) and an improvement of coke quality ( JIS DI $I_{15}^{150}$-actual: $\oplus 1.5$, expected: $\oplus 0.8$ ), an increase of productivity (actual: $11 \%$, expected: $10 \%$ ).

On the other hand, the carry-over to the larry car system and the ascension pipe increased. This affected adversely the gas cleaning process and the tar quality. However, these problems were not substantial and overcame by our operational improvements.

This process has been operating satisfactorily.

\section{Introduction}

In recent years, there has been a remarkable progress in energy-saving at coke ovens. Nippon Steel has installed coke dry quenching $\left(\mathrm{CDQ}^{1)}\right.$ : introduced from "Licensintorg" of USSR) for the recovery of sensible heat of hot coke and automatic coking control systems for the reduction of the energy input to coke ovens. However, the sensible heat of gas generated in coke-oven and of combustion waste gas, which accounts for a large proportion of the energy losses at coke-oven, has scarcely been recovered or utilized.

Nippon Steel has pushed forward with techniques for the recovery and utilization of this sensible heat. In 1982, heat exchangers in ascension pipes using a heat carrying medium came on stream at its Nagoya Works, $\left.{ }^{2}\right)$ enabling part of the sensible heat of gas generated in coke oven to be recovered.

Meanwhile, the preheated coal charging by the Precarbon system was started at the Muroran Works ${ }^{3}$ ) in 1979 and the effect of drying and preheating of coal was confirmed. Paying attentions to the fact that greater savings can be obtained by combining wasteheat recovery techniques with automatic coking control techniques based on these results, we developed a control technique of coal-moisture utilizing the sensible heat recovered from the gas generated in coke oven and combustion waste gas with a view to applying it to existing coke ovens. At Nippon Steel, this process is called "coal-moisture control process" (hereinafter referred to as " CMC"). The first CMC was installed at the Nos. 1 and 2 coke-oven batteries of Oita Works. ${ }^{4}$ )

This equipment was brought into operation in September 1983, and has since been operating satisfactorily, achieving the expected results in energysaving, coke quality, productivity improvement.

This report presents an outline of the equipment and operation results.

\section{Basic Concept of CMC}

Coke-oven operation is greatly influenced by the properties of charging coal. Among other things, variations in the moisture content of charging coal have been a great impediment to the stable operation of coke ovens. (Actual moisture content of charging coal at Oita: 7 to $14 \%, 9 \%$ on the average of one year). These variations occur in a short time and lead to an increase in heat consumption, nonuniform coke quality, variations in production. We have always aimed at an ideal form of operation in which coke oven processes charging coal of which moisture content is always controlled to a constant level regardless of weather. To realize this, we have developed a control technique of moisture in charging coal in which the waste heat from coke oven so far not recovered is effectively utilized, and has recently succeeded in completing this new technique.

This technique is effective in ensuring stable cokeoven operation and protecting oven wall. The following results are obtained by the application of this technique:

1) Decrease in Heat Consumption

(20 Mcal/t-dry coal per $1 \%$ reduction of coal moisture)

* Based on the paper presented to the 107th ISIJ Meeting, April 1984, S2, at Chiba Institute of Technology in Narashino. Manuscript received on December 28, 1985; accepted in the final form on April 11, 1985. (C) 1985 ISIJ

** Oita Works, Nippon Steel Corporation, Oaza Nishinosu, Oita 870.

*** Plant Engineering \& Technical Bureau, Nippon Steel Corporation, Edamitsu, Yahatahigashi-ku, Kitakyushu 805. 
2) Increase in Coke Strength

$$
\left(\mathrm{DI}_{15}^{150}-\mathrm{JIS}+0.8\right)
$$

3) Increase in Productivity

(10\% or more)

When the moisture content of charging coal is decreased, the following phenomena are naturally expected according to the level of controlled moisture content:

(1) The amount of dust and fume generated during the transportation and charging of coal increases.

(2) The carry-over of pulverized coal into the ascension pipe increases during charging and carbonization, thus having an negative effect on the gas cleaning process and worsening the properties of tar.

It is important, therefore, to select the moisture content at such a level that provides the greatest economic benefit evaluated by considering the air pollution, recovered energy, and other expected effects.

\section{Outline of CMC Equipment}

Figure 1 is a flow diagram of CMC. Table 1 gives the main specifications of the equipment and Fig. 2 shows the relationship between coal moisture and heat balance.

Features of this equipment are outlined as follows:

(1) Moisture level was decided on $5 \%$ in equipment planning, considering effects on the dust emission and carry-over, and the amount of recoverable heat.
(2) The whole quantity of charging coal after blending and crushing is dried.

(3) In this process, the sensible heat of combustion waste gas from coke oven and the gas generated in the coke oven is recovered using a heat carrying medium first in the flues and then in the ascension pipe, this heat is utilized at a coal dryer, and the heat carrier is recirculated.

(4) Two heat exchangers at waste gas flues and 78 heat exchangers in ascension popes are installed to obtain the heat source for reducing the moisture content of $260 \mathrm{t}$ of coal/h from 9 to $5 \%$ and the amount of heat is balanced so that the coal can be dried by the recovered heat only. However it is important to control the moisture at a constant level when charging coal becomes wet in the rainfall. One heating furnace is therefore installed to supply heat to the heat carrier so that the moisture can always be controlled at a constant level. (Fig. 2)

(5) It has so far been difficult to continuously measure the moisture content of coal. However, an instrument with high-accuracy was developed for continuous measurement of moisture, which uses an infrared moisture analyzer. Using this instrument, coal moisture can be controlled at any level by a combination of feed-forward and feed-back methods.

(6) Alkyl diphenyl, which has high heat stability and is nonpoisonous, is used as the heat carrying medium.

(7) A cooler is installed for the heat carrier to

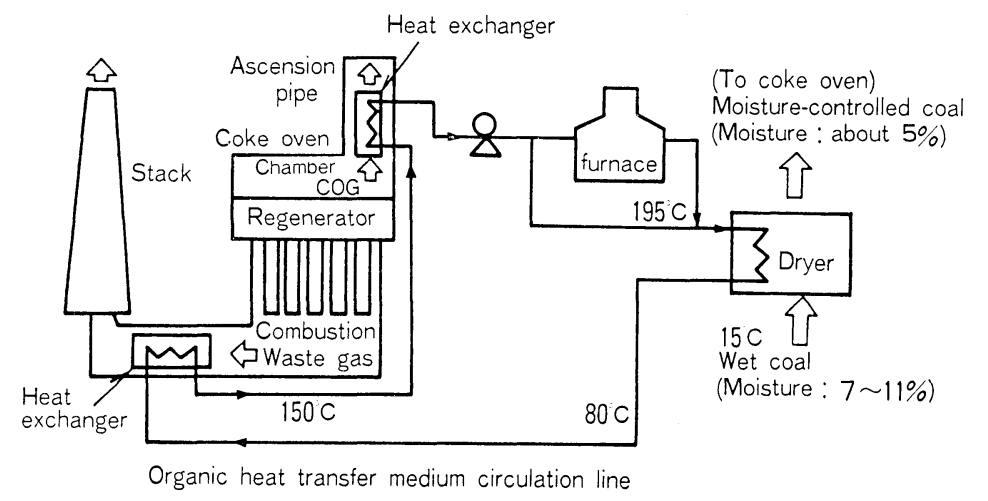

Fig. 1.

Flow diagram of the control process of coal moisture.
Table 1. Main specification of equipment.

\begin{tabular}{|c|c|}
\hline Item & Description \\
\hline 1. Dryer & $\begin{array}{l}\text { Indirect heating rotary } \\
\text { dryer type } \\
260 \mathrm{t} / \mathrm{h} \times 1 \text { set }\end{array}$ \\
\hline $\begin{array}{l}\text { 2. Equipment for heat recovery } \\
\text { 1) Goke oven waste gas } \\
\text { 2) Goke oven gas }\end{array}$ & $\begin{array}{l}1 \mathrm{co}: 4.95 \times 10^{6} \mathrm{kcal} / \mathrm{h} \\
3 \mathrm{co}: 55.40 \times 10^{6} \mathrm{kcal} / \mathrm{h} \\
1 \mathrm{co}: 3.90 \times 10^{6} \mathrm{kcal} / \mathrm{h}\end{array}$ \\
\hline 3. Heating furnace & $3.95 \times 106 \mathrm{kcal} / \mathrm{h} \times 1 \mathrm{set}$ \\
\hline 4. Coal conveyor & $\begin{array}{c}1200 \mathrm{t} / \mathrm{h} \times 4 \text { sets } \\
290 \mathrm{t} / \mathrm{h} \times 1 \mathrm{set}\end{array}$ \\
\hline 5. Bag filter & $1165 \mathrm{~m}^{3} / \mathrm{min} \times 1 \mathrm{set}$ \\
\hline
\end{tabular}

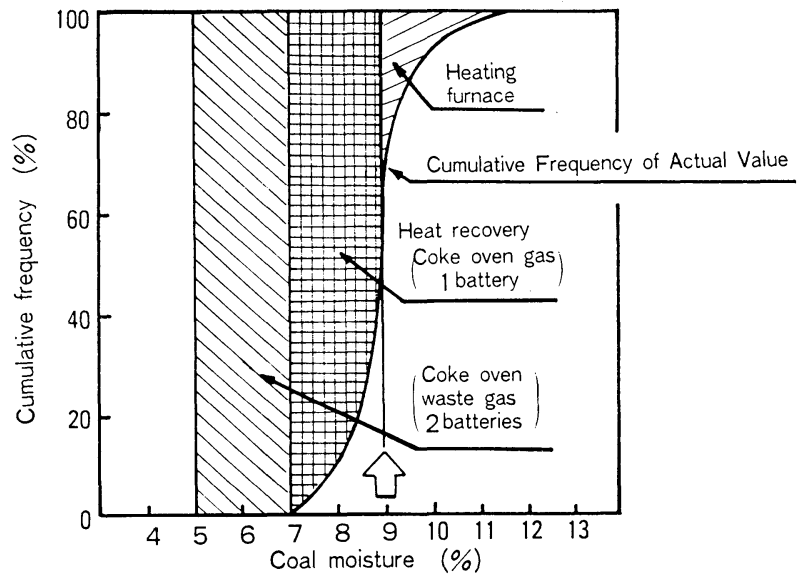

Fig. 2. Relation between energy recovered from coal moisture and additional energy. 
consume the heat recovered during the stoppage of the dryer. Furthermore, the ascension pipe heat exchangers are equipped with a water-cooled jacket in order to prevent abnormal temperature rise of the heat-carrier when the pump to circulate the carrier gets out of order.

(8) Where combustion waste heat is recovered, the existing flue is left as an open by-pass. Therefore, even if the blower is down, the waste gas flows through the existing flue so that the combustion system of the coke oven is not adversely affected.

\section{Operation Results}

CMC equipment came on stream in September 1983. The moisture content of charging coal was gradually decreased and in March 1984, it approached to $5 \%$, the target of moisture content for this equipment. There has been a tendency of increase in steel production since September 1983, and the cokeoven batteries have been operating at increasing working rates and are now operating almost at full capacity. The operation results are very satisfactory.

Figure 3 shows the operation results before and after the start-up of the GMC equipment (in fiscal 1983). Control of coal moisture was conducted in the Nos. 1 and 2 coke-oven batteries.

The effects of CMC and its influence on by-products are described below:

\section{(1) Effect on Heat Consumption}

As a operation results, it was found that heat consumption could be reduced by 80 to $93 \mathrm{Mcal} / \mathrm{t}$-coal by a decrease in the moisture content from 3.4 to $4.1 \%$. This decrease in heat consumption corresponds to 23 to $26 \mathrm{Mcal} / \mathrm{t}$-coal for each $1 \%$ moisture content and exceeds the initially expected value of $20 \mathrm{Mcal} / \mathrm{t}$.

\section{(2) Effect on Coke Strength}

The comparison cannot be made in coke strength in the actual results, because the blending ratio of coal was changed every month.

Therefore, coke strength estimated by SI-CBI diagram $^{5)}$ was compared with actual strength for each blending ratio of coal using average values before and after the start-up of the GMC equipment.

As a result, it was found that $\mathrm{DI}_{15}^{150}$ shows a $1.5 \%$ increase, which exceeds the initially expected value. It may be thought that this improvement in DI is due to an increase in the bulk density of charging coal and the uniform bulk density in the coke-oven chamber. The improvement in DI resulted in a decrease in the yield of coke breeze of $2 \%$ or more. (screen size $27 \mathrm{~mm} \times 27 \mathrm{~mm}$ ) Thus, this process offers very great economic benefits resulting from quality improvement.

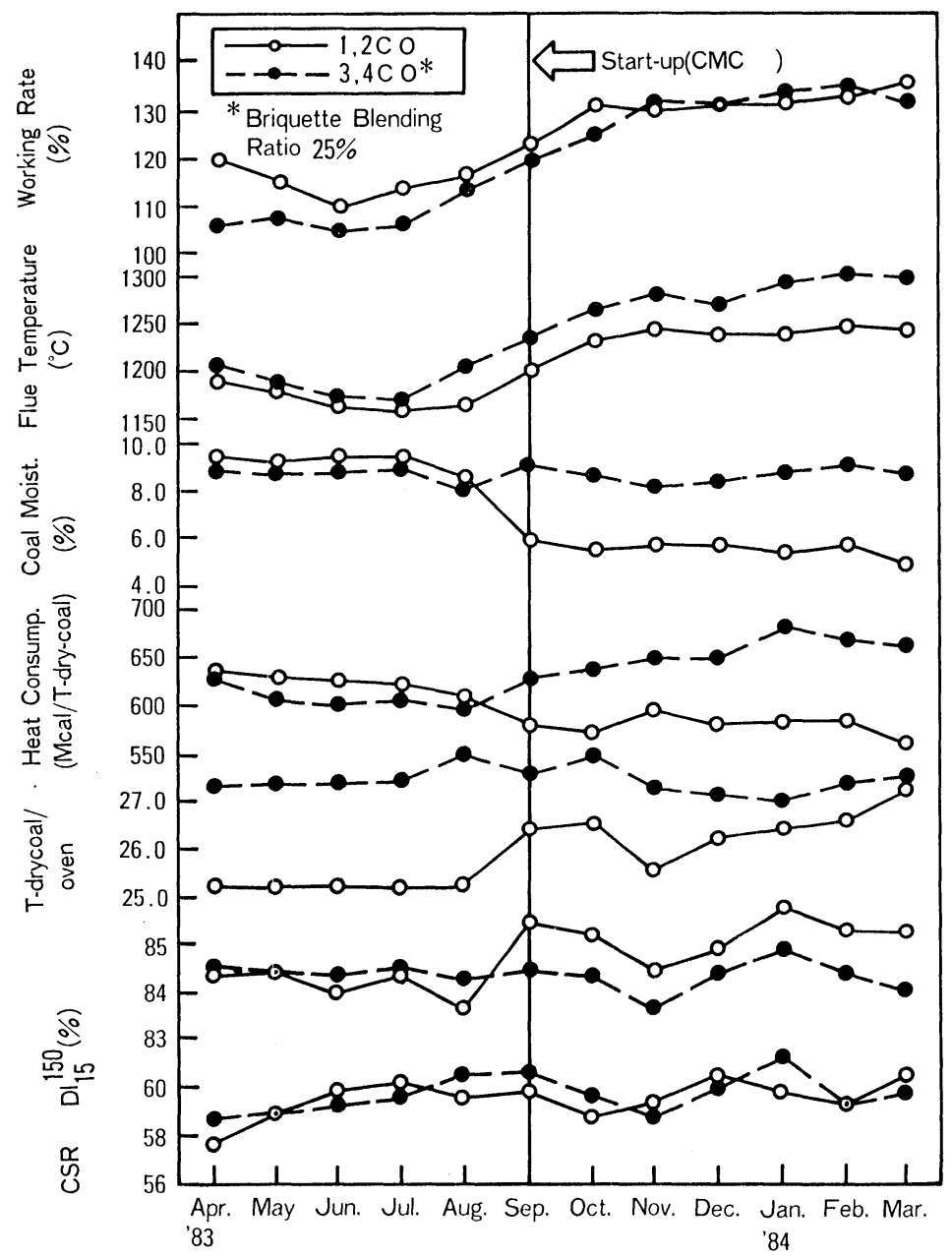

Fig. 3. Operation results of Oita coke-oven batteries. 


\section{(3) Effect on Productivity}

Productivity increases because an increase in the bulk density of charging coal and a decrease in the coking time can be simultaneously achieved by CMC. When moisture content is decreased from 9 to $5 \%$, the bulk density increases by $6.9 \%$ and the coking time decreases by $3.7 \%$. Therefore, productivity increases by about $11 \%$, which exceeds the expected value. (See Fig. 4.)

\section{(4) Effects on Dust Carry-over and By-products}

Figure 5 shows examples of measured carry-over. The carry-over to the larry car system and ascension pipe increases with decreasing moisture content and is about 3.5 times and 1.5 times respectively of the level before moisture control on the average during the just after charging. The relationship between the carryover to the ascension pipe and the time elapsed after charging shows that the carry-over decreased substantially in first $10 \mathrm{~min}$. But the carry-over is a little larger in the case of moisture control than that with wet coal charging. However, this does not impede smooth coke-oven operation greatly and operation can be smoothly conducted simply by cleaning the dust collecting ducts and ascension pipe. In the gas cleaning process, same influences were observed in the separation of liquid ammonia in the tar decanter, the operation of the primary cooler and tar strainer, etc. However, this problem can be solved by raising the decanter temperature and increasing the frequency of cleaning of the cooler. No troubles have occurred at all in the system to process liquid ammonia (biological treatment).

During the investigation period, great changes in operation conditions occurred due to a decrease in the volatile matter of coking coal and an increase in the working rate of the coke oven. Therefore, these changes affected the amount of by-products. However, there is no noticeable influence of CMC on the amount of by-product.
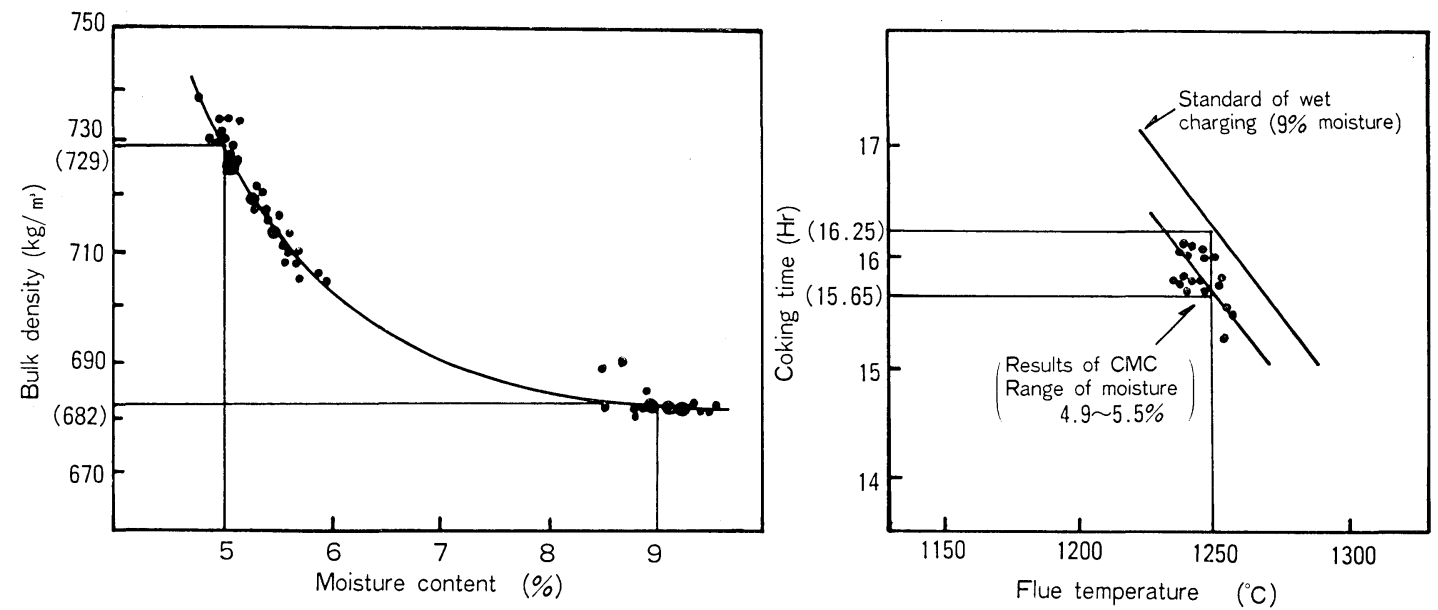

Fig. 4. Effect of CMC process on productivity.
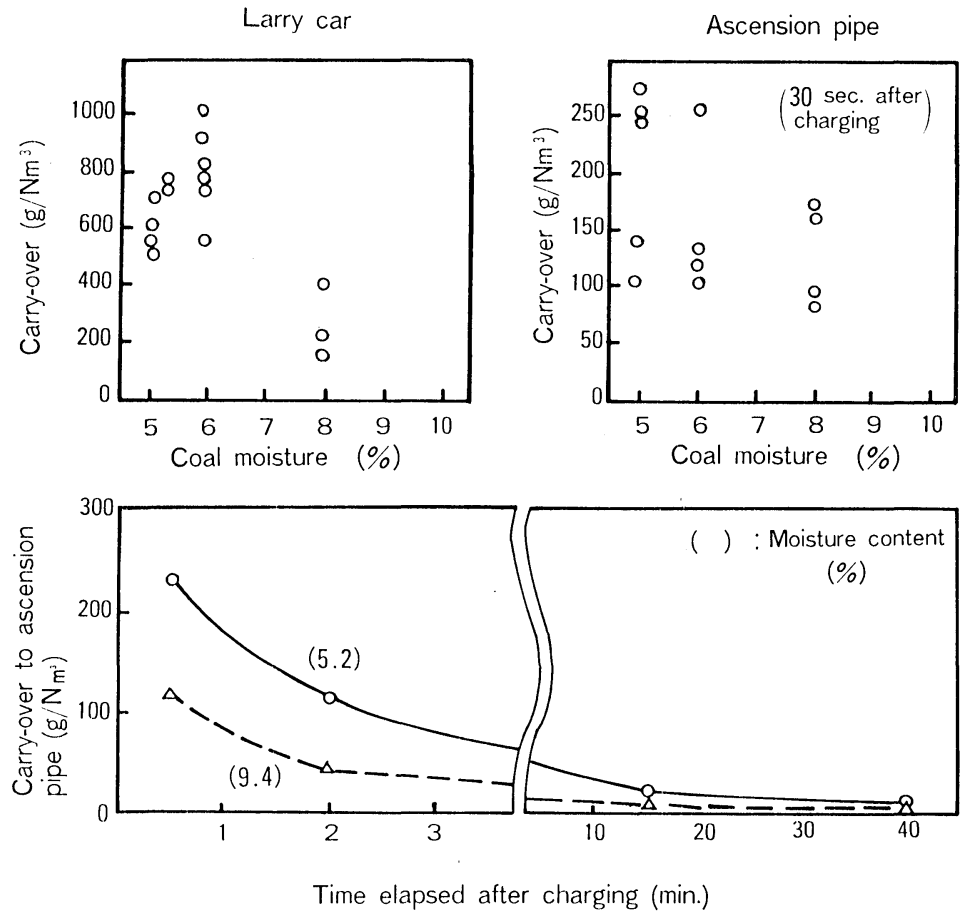

Fig. 5.

Changes in the relation between coal moisture and carry-over. 


\section{Conclusion}

The control equipment of coal moisture using waste heat from coke ovens at Nos. 1 and 2 coke oven batteries of Oita Works, has been operating satisfactorily.

The operation results are as follows:

(1) Increase in productivity is about $11 \%$ by increase of bulk density and decrease of coking time.

(2) Decrease in heat consumption is $23 \sim 26$ Mcal/t-dry coal per $1 \%$ coal moisture reduction.

(3) Increase in coke strength (JIS DI ${ }_{15}^{15}$ ) is $1.5 \%$, as a result decrease in the yield of coke breeze is $2.0 \%$ or more.

(4) The carry-over increases a little. However, the influence of this to the coke-oven operation can be solved by operational technique.

(5) The yields of by-products is little change.

\section{REFERENCES}

1) T. Sasaki and I. Komaki: Coke Circular, 26 (1977), 193.

2) S. Uwano, K. Ikai, N. Inoue, S. Fujiyoshi, K. Kawanishi and E. Ogino: Tetsu-to-Hagané, 69 (1983), S51.

3) A. Suzawa, H. Kamoya, T. Iguchi, T. Okazaki, K. Kushioka and H. Ogawa: Tetsu-to-Hagané, 67 (1981), S116.

4) K. Nagano: Coke Circular, 22 (1973), 212.

5) N. Shapiro: AIME Blast Furn. Coke Oven \& Raw Mat. Comm. Proc., 20 (1961), 89.

6) K. Kojima: J. of the Fuel Soc. of Japan, 50 (1971), 894. 